\title{
Occupied by design: evaluating performative tactics for more sustainable shared city space in private-led regeneration projects
}

\author{
S. M. Golden \\ Belfast School of Architecture, University of Ulster, UK
}

\begin{abstract}
This paper investigates alternative approaches to statutory consultations in privateled regeneration projects. It explores decision-making processes for more locally relevant, place-based investments in shared urban space. It presents practice-led research about performative tactics, open-ended investigative action, to influence traditional processes of development and statutory consultation toward greater social sustainability. It focuses on the example of a temporary legal streetoccupation, an activention, in Belfast, Northern Ireland. The occupation responded to proposals to create a new public square as an "iconic meeting place" to spur regeneration in an existing marginalized neighbourhood. The paper argues that the formal proposals were based on top-down strategies that set-out limiting detailed designs based on the input of "key stakeholders" and consultants. Using anonymous surveys from event participants and public-private stakeholders, the paper compares and contrasts perspectives about more experimental visioning and consultation tactics, drawn from global thinkers and practitioners. It aims to foster deeper public-private-government conversations about existing public space qualities and place-driven potential. Through a reflective discussion, the author's actions as an architect are also considered. An evidence-based argument, contextualized within UK and wider global discourse on sustainable communities, sets out how open-ended and performative strategies are perceived as a positive foil to more closed development decision-making, and can contribute to more proactive engagement with the public. Findings also support a greater focus on performative skills as means for architects to (re)frame their creative knowledge as tools for more transformative practices in complex city contexts.
\end{abstract}

Keywords: lighter-quicker-cheaper activention, place, public space, Belfast sustainability, regeneration, participation, architecture, performative tactics. 


\section{Introduction}

[R]egeneration programmes have too often concentrated on changing buildings, rather than helping people...Past experience has shown that massive investment can be made in building or refurbishing residential or business property with very little impact on local people [1, p. 29].

Since the late 1990s regeneration has become one of the central and highly contested planning and urban policies of successive UK governments [2, 3]. Regeneration aims include the re-use and rejuvenation of what are typically regarded as marginalized, impoverished, or underperforming areas of cities. Regeneration schemes often include social and economic claims that publicprivate investment can target what are characterized as unsuccessful and deprived inner-city areas to transform them into inclusive, sustainable and prosperous places. To correlate market-led designs and investment ambitions with highquality environments and community-centred aspirations, urban policies, design masterplans, and development brochures also commonly adopt loaded terms such as place-making, participation, and sustainability [4]. Evidence suggests that despite inclusive claims many regeneration schemes offer little more than top-down place-(re)branding and surface solutions [5] with limited public consultation about the quality of the public realm $[6,7]$. In many examples, fully-formed design proposals are presented to the public for cursory comment; often on the assumption that the developed proposals will proceed with minor modifications to planning and implementation stages.

Using an example of public-private development in Belfast, Northern Ireland, this paper analyses and compares open-ended and experimental consultation strategies with more traditional closed methods. It focuses onto a series of public events, organized by the author in 2013, which responded to what was perceived as a costly, fragmented, and top-down proposal from the Department for Social Development (DSD) for a new public square called Library Square. The events, which were open to the public, culminated in a temporary legal occupation - an 'activention' - in the proposed development site, using collaborative and low-cost experimental tactics to widen awareness about the project and contribute to formal statutory consultation processes. The events relate to globally recognised "lighter, quicker, cheaper (LQC)" tactics, which promote the use of low-cost, "incremental, [and] locally-based" interventions to encourage wider discussion about local place meaning and highlight "alternative[s] to capital-heavy, top-down planning" [8].

The paper contextualizes the events and local decision-making processes within global discourse about private-led urban regeneration, participation, place-meaning, and priorities for public infrastructure and shared space. It also focuses on the author's perspective as an architect to address wider questions about architects' and other built environment professionals' roles in the planning, design, and delivery of larger-scale market-oriented urban projects. Findings suggest performative open-ended tactics improve how diverse actors and stakeholders effectively contribute to discussions about places people share. 


\section{Objectives and methodology}

The research extends and analyses the impact of the February 2013 activention and related activities that ran in parallel to DSD's statutory consultations. The pop-up event and street occupation, combined with a public workshop led by the author, gathered responses about the proposed new public square into a formal submission to DSD's consultation. The research aims to assess the pop-up events with feedback from event participants as well as key stakeholders involved with the Library Square design, planning, and funding. It also aims to contribute directly into ongoing research and policy development about what tactics and skills might better assist the delivery of more grounded place-based proposals for (re)developing existing and expanding urban areas $[9,10]$.

The methodology combines the author's reflective account of the activention process with data from anonymous and ethically approved surveys carried out between January and April 2014. The surveys focus onto perceptions about how effective informal consultation tactics were in raising awareness about development proposals compared to DSD's more formal process. Additional quantitative survey data helps illustrate the scope of participants and provides some insight into how the feedback gathered through the pop-up events contributed to the more formal consultation and DSD's responses.

A review of supporting research examines the broader debates about contested processes of regeneration in inhabited urban areas. It aligns with arguments that where development is top-down or seen as counter to local visions, "[s]trong spatial conflicts" can develop, based on the "struggles [with issues] of inequality [...and] collective resistance to processes of gentrification, discrimination and exclusion" [11]. While the scope of these global questions goes beyond the present paper, its findings are relevant to debates about urban practice and wider decisionmaking processes in dynamic city contexts.

By engaging with the public and with private, community, and government institutions the research acknowledges that whether development projects are driven by local communities or through private, market-driven frameworks, many actors play a role in shaping the physical and socio-cultural or economic character of new buildings and public-spaces.

\section{Background: Library Square}

In November 2012, the DSD announced public consultations for the new $£ 3$ million (\$5million) pedestrianized public space of Library Square. Design proposals include a joint government and private-led public realm scheme to transform an existing street into a new "landmark" and "iconic meeting place" [12] (Fig. 1). The proposal is set within a context of existing Victorian-era buildings, including Belfast's historic Central Library, and is within 300 metres of Belfast's central business district and several surrounding retail, cultural, and education based developments (Fig. 2). The design concept centres around literary-themed paving and fixed seating, tree sculptures, retail kiosks, large video screens and Wi-Fi hotspots (Fig. 3). 


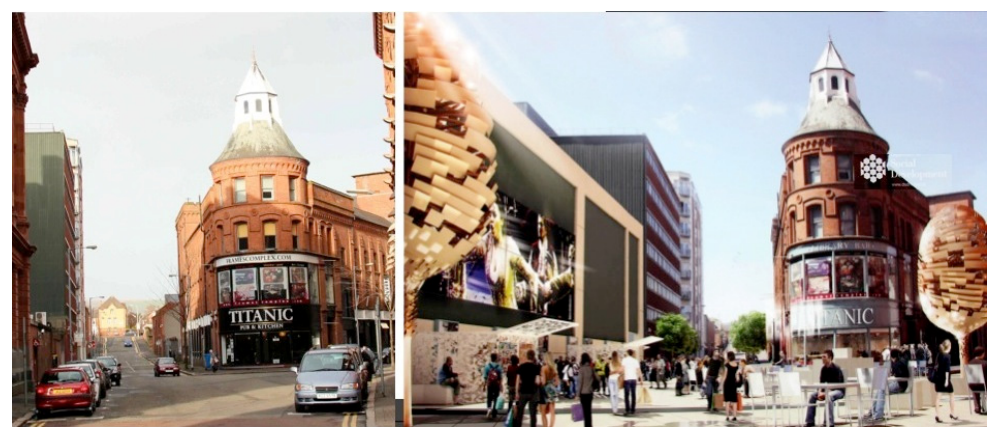

Figure 1: Existing and proposed Library Street (source: URB, author; DSD).

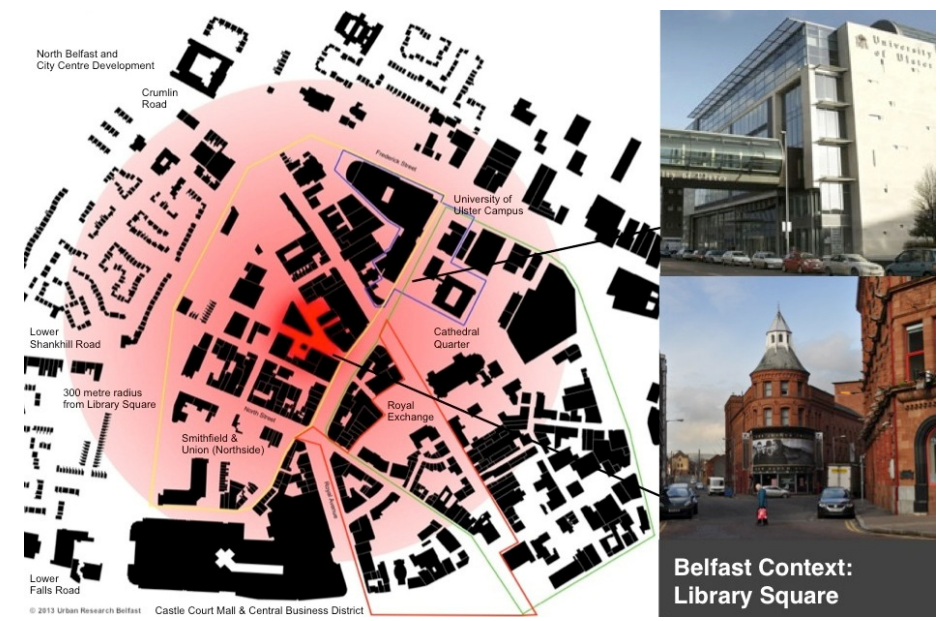

Figure 2: Map of Library Square and North Belfast city context (source: URB, author).

Public consultations were open from November 2012 until February 2013, set out by DSD as consideration of comments and equality screening for the "final designs" in anticipation of taking the concept forward to a business case review and planning application. Announcements about the final design and consultation were disseminated by local press, information on DSD's website (www.dsdni.gov.uk), and colour brochures in public buildings.

Prior to the public consultation, DSD developed the Library Square concept with external "expert masterplan" consultants Benoy and Peter Brett Associates, and project managers, Drivers Jonas Deloitte. DSD had also engaged private developers in 2011, putting out a call for expressions of interest "in regenerating vacant sites in the area around the Central Library", including the pedestrianized square as "the [high-quality] heart of the scheme" in order to promote "a new café culture" [13]. Input from the wider community prior to the public consultation was limited to "key stakeholders" from larger business, statutory bodies and public institutions. 


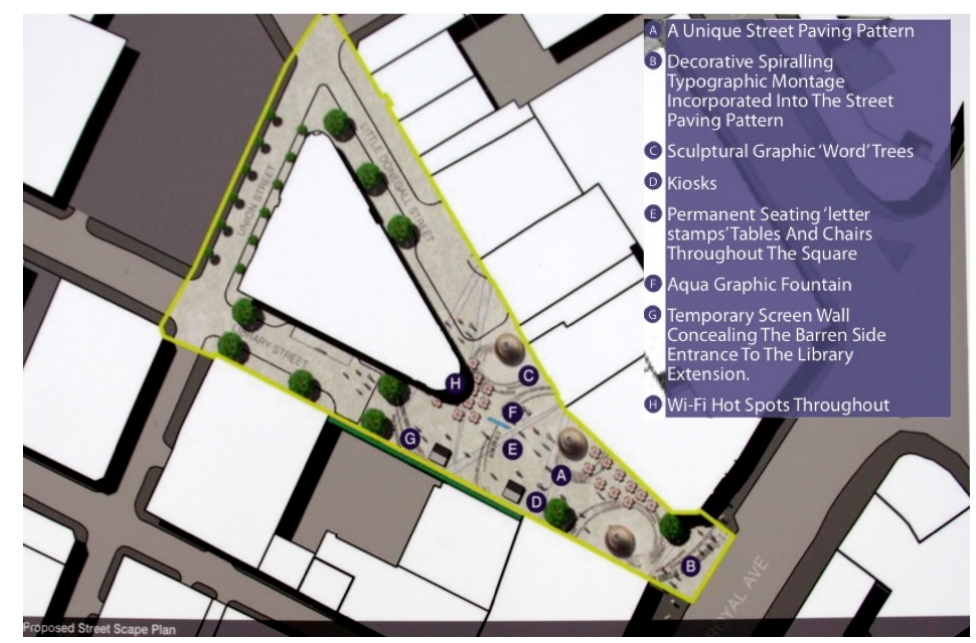

Figure 3: $\quad$ Proposed streetscape and public realm design features (source: DSD).

During the latter stages of the consultation period, two public venues exhibited information about the proposals; one in Belfast Central Library (21-25 January 2013) and another in the lobby of the University of Ulster's Belfast Campus (28 January-1 February 2013). The exhibitions were held near the end of the consultation period and consisted of poster displays, brochures and printed comment forms. Each location was staffed by representatives from DSD to answer questions the exhibitions. There was no additional public presentations or feedback sessions.

Following the close of consultations, the Library Square project was integrated into a larger city-wide public realm scheme called "Streets Ahead." DSD issued responses to Library Square comments in October 2013 and announced a second stage of design development with aims to proceed to planning in 2014-15.

\section{Reflecting on action and activention}

The term activention refers to "positive occupation" of public space, a mix of activism and spatial intervention [14]. Activist measures were not initially part of efforts to raise debate and awareness about the proposals for the public realm around Library Square. This section provides some background about how early engagement with traditional consultation processes transformed from conversations to pro-active strategies.

An initial public workshop to coincide with DSD's exhibition at the University of Ulster Belfast campus in February 2013 was organized by the author through Urban Research Belfast (URB), a collaborative within the Faculty of Art, Design and the Built Environment. DSD loaned their information boards for a presentation to local business owners, government representatives, and local residents. Contributors included the Chair of Northern Ireland's Ministerial 
Advisory Group on Architecture and the Built Environment (MAG), Arthur Acheson. The opening presentations from URB, and MAG argued against capital spending on new structures and retail kiosks, focusing on alternative possibilities for activating the space by investing in building partnerships between local businesses, and on managing street-level activity. A surprising outcome of the early conversations was that local people - lay people and business owners viewed any form of investment as favourable, and were wary that negative comments might result in no investment at all. The lesson from this experience was that starting out negatively and assuming a role of 'expert designers' risked alienating people and cutting off opportunities for deeper conversation.

When discussions focused more positively on potential economic benefits for public bodies to work with investors, property owners, and the public as partners, there was greater willingness to consider how investments in cultural programmes and existing amenities might support new street-level activity that relied less on an already struggling retail-led business model. Ideas became more fluid and led to the first proposals for action; a small step, borrowing a table and chairs from a restaurant adjacent to the proposed square and moving the discussions into the street itself. That in-situ interaction provided an outlet for debates and a by-product of engaging directly with passers-by, who typically gave a double-take and a smile. From this step it was a spontaneous leap to agree to a week-long collaborative process that culminated in the temporary closure of the street. The lesson from this process was the importance of recognizing and reacting flexibly to key opportunities and people as they presented themselves.

With no formal advertising or funding, the event was proposed as a pop-up 'positive occupation.' Before taking over the street however, it was important to get as much legal and local buy-in as possible. Occupying a public space in any city can be contentious, and Belfast is no exception. Belfast has a long history of negative, and at times violent sectarian conflict over sharing space as well as more recent examples of global Occupy movements in public spaces and private buildings. To legally occupy footpaths, car-parking, and roads involved working with likeminded individuals as well as voluntary and statutory organisations. A key catalyst for events to proceed from idea to action in just over a week was the additional unexpected support from Northern Ireland's Police Service (PSNI) and the Belfast Central Library.

For example, the Police Service initially questioned plans to occupy the street but, after meeting on site, the neighbourhood Constable took an encouraging approach to the event's temporary and positive aims. The PSNI also helped close the street on the day of the activention. Similarly, the Library manager, who raised concerns over service access throughout the event, recognized how a successful public space could be mutually beneficial for the library and gave crucial backing to the event. A serendipitous encounter involved meeting a community poetry society, The Shalom House Writer's Club, who held recitals in the Library and agreed to a live poetry reading in the street. These diverse experiences reveal that you never know where the "right" people will come from, so it's best to talk to everyone. A growing network of volunteers secured the event. Key contributors included local businesses, MAG, the Belfast School of Architecture, and PLACE 
(Northern Ireland's Architecture and Built Environment charity). PLACE involved Somewhere To..., a UK-wide initiative with youths under the age of 25 in projects affecting the physical environment. PLACE also donated furniture and fake grass, and invited a street artist, Jane Butler, to develop chalk-art activities.

\subsection{Action, experimentation, and interaction}

On the day of the activention volunteers and local businesses helped set out the street with areas for play and seating: hopscotch and an impromptu badminton court in the street, an old guitar for budding buskers, and an outdoor café from donated furniture and fake grass. Young people worked with the street artist to 'cultivate' chalk grass and flowers over the asphalt parking spaces and up some blank walls facing the square. Despite a cold February day, a steady stream of people joined in the poetry readings, games, guitar, art, and general conversation, encouraged by more coffee from the Library café, and sandwiches from a local restaurant owner. Members of the public, design professionals, public artists, and representatives of DSD participated. During the afternoon curious members of the public also stopped to ask about the event and the official design proposals. A few harmless hecklers added to a lively, interactive public display (Fig. 4).

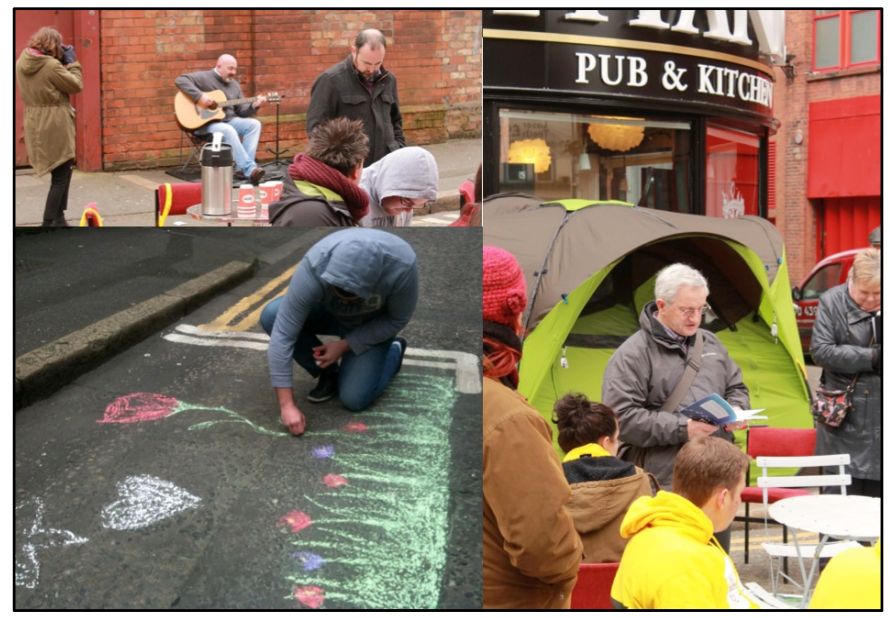

Figure 4: Activention day, clockwise from top left; impromptu busking, outdoor cafe and poetry reading, asphalt chalk art (source: URB).

\subsection{Gathering ideas}

Without formal marketing, the pop-up event attracted attention and received press coverage about the potential for the proposed Square to be a better quality place without kiosks or overly expensive design [15]. Some key members from DSD who ventured out to visit the activated street, saw for themselves what the temporary activity was trying to achieve. Comments, stories, and ideas were gathered during the day from the public and volunteers. Suggestions including 
ideas for flexible uses such as street-markets or other cultural events were compiled by URB and submitted to DSD's consultation. At the end of the afternoon all that was left behind was an inspirational and colourful chalk meadow.

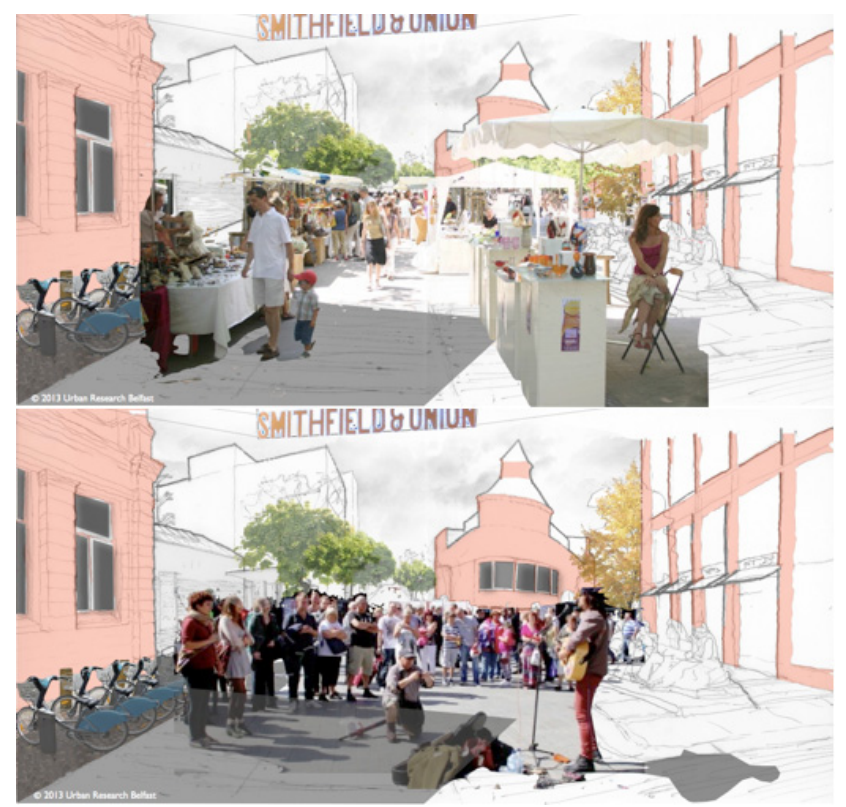

Figure 5: Illustrated comments, markets and cultural events (source: URB).

\section{Assessing impact}

In October 2013, DSD published a compilation of consultation comments and their responses, grouped by themes: urban design-street furniture, urban designscreen, urban design (inclement weather), scheme vision/concept, access, and wider regeneration [16]. From a total of 29 individual submissions, DSD extracted 35 comments; 9 were direct quotations and a further 4 were paraphrased from the URB event submission, collected from feedback during the single afternoon of street interaction with the public. In relation to all feedback selected for a response by DSD from their 3-month consultation period, 33\% derived from the single informal activention day.

\subsection{URB survey: preparation and selection pool}

The gap in the quantity of feedback from the more traditional methods prompted the author to undertake further research; to survey participants who had provided details during the activention day, and to also survey key stakeholders from DSD, Roads Service, MAG, PLACE, and local businesses. While not exhaustive, the intention of the survey research was to uncover further lessons about how people 
engage or ignore development proposals, the views of designers and statutory representatives about traditional versus more interactive methods of engagement, and what support there might be for more open-ended strategies to become a more 'official' part of future consultations.

To gather responses from the identified selection pool (Table 1) anonymous paper surveys were selected and developed through the University's research governance and ethics committee. Paper surveys have an average of 56\% return, higher than typical online options, particularly when issued directly to participants [17]. Given the limited number of potential participants the surveys were distributed by post or in person with a personal message. A stamped returnenvelope was also included to help participants maintain anonymity if required. Recruited participants were given an option to identify their involvement in either the event or developing the proposals. While the returns were less than expected, at $48 \%$, they are within an acceptable range with a high proportion of returns including information to provide some breakdown of the respondent profile compared to those recruited.

Table 1: Distribution and return of anonymous surveys (source: author).

\begin{tabular}{|c|c|c|}
\hline Survey Selection: Event Participants and Stakeholders & Issued & Returned* \\
\hline Members of the public & 15 & 3 \\
\hline Design and Planning Professionals & 08 & 5 \\
\hline Representatives of Statutory Organizations & 05 & 1 \\
\hline Representatives of Voluntary Organizations & 10 & 6 \\
\hline Belfast Central Library Staff & 02 & - \\
\hline Students and Staff, Belfast School of Architecture & 18 & 5 \\
\hline & & $7 * *$ \\
\hline Total & 58 & 27 \\
\hline
\end{tabular}

* Respondents given option to identify selection group. ${ }^{* *}$ No identification returned.

\subsection{URB survey: question structure}

Questionnaires mainly focused onto qualitative feedback through a mix of open and closed questions and themes: involvement in consultation and project proposals, sources of information about development, reasons for responding or not responding to traditional consultation, priorities for investment and development impacting public space, perceptions of the pop-up street event, comments on statutory consultations and quality of the public realm. A limited number of optional quantitative questions asked for information about age, gender, and each participant's organization or role in the project as an aid to identifying and discussing the scope of responses. 


\subsection{Overview of survey findings}

An overview of survey responses suggests that, with qualifications, performative tactics can be a viable and economically efficient way for the public to contribute to strategic planning and design consultation at earlier stages of (re)development considerations. A common reason that respondents gave for not submitting comments about proposals using DSD's structured response forms was because of a lack of awareness or access to the form, available online.

Those respondents who noted they contributed to either the DSD or the URB consultation were asked to rank priorities for a range of development issues: General (visioning, strategy), Particular (concept, themes), Detail (finishing, furnishing, architectural elements), Technical (environment and infrastructure), Management (staffing, maintenance), Economic (investment, funding, costs), Social (shared space, accessibility), Consultation (public input). Answers reflect a diverse set of concerns with little consensus. Students and some professionals ranked social issues highest and management or economic issues lowest. In contrast the responses from businesses and local interest groups focused on economics and specific details first, with consultation and technical issues last. The diversity is perhaps not surprising and might reflect more on the profile of students and professionals who choose to take part in activist type interventions and events.

Responses reflected a predominant, but not exclusive, view that the pop-up event was more effective than pre-selected proposals from design teams or competitions for consultation. An architect added that the pop-up event needed to be more "aligned with pro-active engagement" to be effective. The scope of agreement was spread evenly about whether computer-renderings were never, sometimes, or always appropriate. Those who felt that pre-prepared design proposals and computer-models were value for money, before consultations, shared a view that such tools could help understand the impacts of "quality of the public realm" but would not be effective to determine if the proposals themselves were "good value for money." One response from an architect/planner noted that design investigations prior to public consultations would be value for money if limited to "design strategies," not for proposals.

A member of the public provided a unique response, noting they felt that the pop-up event "helped inform people of the past usage and the history of the space" while also noting that it changed their mind in favour of DSD's proposal: It proved that DSDNI were about creating better spaces for the public.

One government adviser, who was critical of both the value for money and the quality outcomes of design and building focused schemes, provided a contrasting extended response:

Schemes are still being produced as DESIGN only, with no or very little work being done on learning from management to inform design and then to be able to transfer good management techniques to the newly designed places. This needs serious re-consideration [to] highlight the economic inadequacy of the current system as well as its social and environmental failings. 


\section{Conclusions}

A large body of research supports arguments that high-quality public spaces are key to economically and socially successful urban environments [18]. There is less consensus about what constitutes a successful public space, what are the best strategies to deliver successful places, and who should contribute to decisions affecting built environment futures; particularly in existing cities. Research on attitudes and levels of participation about development concludes that there is a lack of engagement between the public and professionals, policy makers or developers in planning and designing, or delivering regeneration projects $[19,20]$. This paper has set out an example where performative tactics, drawing from performance art and sociological practices, can apply to urban design and public consultation as an investigative approach that combines action with an open-ended interest in transformative knowledge [21, 22]. It argues engaging both development proposals and the public without an expectation of conclusive outcomes offers an alternative or at least a moderating foil to more normative 'expert designer' approaches.

The range of participants and gathered responses from the author's short-term activention suggest that a desire exists for different methods of public engagement on design proposals impacting the public realm. Survey responses and initial analysis of the author's pop-up event seem to support arguments that performative tactics can contribute to both a better understanding of a local area's incremental potential as well as testing out larger-scale strategic issues before committing to a set design. The balance appears to be in the earliest combination of performative tactics and widest possible level of pro-active engagement, aiming not for 'buyin' but for a deeper understandings about place that can contribute to more relevant, sustainable development of public space.

\section{Acknowledgements}

The author would like to thank all those who contributed time and resources to the activention and Library Square consultation process in February 2013. Portions of the reflective account in this paper are adapted from the author's previously published blog post for Project for Public Spaces Ltd. [14]. Additional editorial and content advice was received from Dr. Taina Rikala and Professor Ian Montgomery, University of Ulster; and Arthur Acheson, MAG.

\section{References}

[1] Social Exclusion Unit, "National Strategy for Neighbourhood Renewal: a framework for consultation," Crown, Apr. 2000.

[2] Lees, L. "Visions of "urban renaissance"" in Urban Renaissance? New Labour, Community and Urban Policy, R. Imrie and M. Raco, Eds. The Policy Press, 2003, pp. 61-82. 
[3] DCLG, "Regeneration to enable growth: A toolkit supporting communityled regeneration," Crown, London, 2012.

[4] Rydin, Y. Governing for Sustainable Urban Development, 1 edition. London ; Washington, DC: Routledge, 2010.

[5] Porter, N. "Place branding and urban design: intangible values and tangible effects," in Proceedings: Designing Place, International Urban Design Conference, Nottingham, UK, 2-4 April 2012, pp. 488-506.

[6] CABE, "New Localism and community engagement: What it means for public space quality,” DETR, London, Jun. 2006.

[7] Jenkins P. and Forsyth, L. Architecture, participation and society. London; New York: Routledge, 2010.

[8] Project for Public Spaces, "Lighter, Quicker, Cheaper: A Low-Cost, HighImpact Approach.” http:/www.pps.org/reference/lighter-quicker-cheapera-low-cost-high-impact-approach/. [19-May-2014].

[9] UN-Habitat, "Planning Sustainable Cities," UN-Habitat, 2009.

[10] "Post 2015 Agenda - UN-Habitat." http://unhabitat.org/urban-initiatives2/post-2015-agenda/ [10-May-2014].

[11] Di Masso, A. et al., "On the contested nature of place: 'Figuera's Well', 'The Hole of Shame' and the ideological struggle over public space in Barcelona," J. Environ. Psychol., vol. 31, no. 3, pp. 231-244, 2011.

[12] BCCRD, "Library Square Regeneration Scheme," 21-Nov-2012. http://www.dsdni.gov.uk/ [23-Nov-2012].

[13] Stewart, L. "Seeds of regeneration sown in rundown Belfast area," BelfastTelegraph.co.uk, 22-Feb-2011.

[14] Golden, S. "Starting With the Petunias: LQC Action for Better Public Space," Project for Public Spaces. http://www.pps.org/ [19-May-2014].

[15] Short, E. "Crazy paving areas that could transform city," North Belfast News, Belfast, p. 19, 02-Mar-2013.

[16] BRO, "Library Square Public Realm Scheme Consultation Responses," 04Oct-2013. http://www.dsdni.gov.uk/ [19-May-2014].

[17] Nulty, D. "The adequacy of response rates to online and paper surveys: what can be done?" Assess. Eval. High. Educ., vol. 33, no. 3, pp. 301-314, Jun. 2008.

[18] Dempsey, N. et al. Place-Keeping: Open Space Management in Practice. New York: Routledge, 2014.

[19] DCLG, "Communities in control: Real people, real power," Crown, London, 2008.

[20] McAllister, R. "Toward Inclusion? How Belfast Plans Its Regeneration", Queens University of Belfast, Belfast, 2008.

[21] Gaffikin F. and K. Sterrett, K. "New Visions for Old Cities: The Role of Visioning in Planning," Plan. Theory Pract., vol. 7, no. 2, pp. 159-178, Jun. 2006.

[22] Fourcade, M. "The Politics of Method and Its Agentic, Performative, and Ontological Others," Soc. Sci. Hist., vol. 31, no. 1, pp. 107-114, 2007.

[23] Gadahno, P. "Architecture as Performance," http://shrapnelcontemporary.wordpress.com/ [20-May-2013]. 